Note

\title{
Thyroid Stimulating Antibody in Sera of Graves' Ophthalmopathy Patients as a Possible Marker for Predicting the Efficacy of Methylprednisolone Pulse Therapy
}

\author{
SHIGEKI MORI, NORIO YOSHIKAWA, MASATERU HORIMOTO, \\ MASAYOSHI YOSHIMURA, YOSHIFUMI OGAWA, \\ Mitsushige NISHIKAWA, AND MitsUO INADA
}

Second Department of Internal Medicine, Kansai Medical University, Moriguchi, Osaka 570, Japan

\begin{abstract}
Nine patients with Graves' ophthalmopathy (GO) were treated with intravenous methylprednisolone pulse therapy and followed up by ophthalmological assessment, magnetic resonance imaging, and thyroid-associated autoantibody (thyroid stimulating antibody (TSAb), TSH binding inhibitor immunoglobulins (TBII), and anti-eye muscle antibody (EMAb)). Ophthalmological assessment was performed by the ophthalmopathy index (OI) which was made on the basis of the system recommended by the American Thyroid Association Committee. EMAb was expressed as the ratio of density of the $64 \mathrm{kDa}$ band of eye muscle membrane to that of $92 \mathrm{kDa}$ non-specific band found with all normal sera when assessed by western blotting. Five patients with mild ophthalmopathy $(\mathrm{OI}<4)$ did not show progressive improvement in OI. Three of 4 patients with severe eye disease $(\mathrm{OI}>4)$ showed a progressive and distinct improvement in OI. These 3 patients had high TSAb levels before methylprednisolone pulse therapy. One patient with severe ophthalmopathy did not respond to this pulse therapy; this patient's TSAb was negative. A significant positive correlation was observed between the activity of TSAb before treatment and the improvement in OI $(\triangle \mathrm{OI})(\mathrm{r}=0.86, P<0.01, \mathrm{n}=9)$. The relationship between $\triangle \mathrm{OI}$ and EMAb did not reach significance. These results suggest that TSAb in sera of GO patients can be a useful marker for predicting the efficacy of methylprednisolone pulse therapy.
\end{abstract}

Key words: Thyroid stimulating antibody, Graves' ophthalmopathy, Steroid pulse therapy, Anti-eye muscle antibody

(Endocrine Journal 42: 441-448, 1995)

GRAVES' ophthalmopathy (GO) is a progressive inflammatory disorder of the extraocular muscles and now considered to be autoimmune in nature [1]. Currently, the view which seems to be prevailing is that there may be ocular antigens which cross-react with thyroid antigens so that GO would

Received: August 29, 1994

Accepted: February 3, 1995

Correspondence to: Dr. Mitsushige NISHIKAWA, Second Department of Internal Medicine, Kansai Medical University, 10-15 Moriguchi, Osaka 570, Japan be considered inseparable from autoimmune thyroid disease (AITD) [2-4].

Hiromatsu et al. have detected serum eye muscle antibodies (EMAb) in Japanese patients with GO by quantitative analysis of western blotting with rat eye muscle membrane antigens [5], but its precise role(s) in GO and the nature of the corresponding target antigens have not yet been elucidated.

It has recently been suggested that the retroorbital fibroblast represents the target tissue in GO 
[6]. GO is currently unpreventable and the condition is usually treated only when the symptoms become serious or vision is affected. Various therapeutic trials have been reported, for example, corticosteroids [7-11], supervoltage orbital radiation [12], cyclosporine A [13], immunoglobulin [14], and plasmapheresis [15-16]. The results of some of these trials have often been controversial, indicating that none of these therapies is satisfactory and that it is difficult to establish the best strategy for the management of GO.

Corticosteroids have been widely used, and a good effect on GO has been reported [7-11]. Among them, high-dose intravenous methylprednisolone pulse therapy has been reported to be effective in the treatment of GO [9-10], but thus far there have been no established indices for the efficacy of methylprednisolone pulse therapy in GO patients. We have recently reported the positive correlation of orbital muscle changes with magnetic resonance imaging (MRI) and thyroid-stimulating antibody (TSAb) in patients with GO [17]. In the present study, we have attempted to study the relationship between thyroid associated autoantibodies and the efficacy of the methylprednisolone pulse therapy in patients with $\mathrm{GO}$, hoping to find some useful markers for the prediction of the efficacy of intravenous methylprednisolone therapy.

\section{Materials and Methods}

\section{Subjects}

Nine patients with GO (6 women and 3 men; mean age, $40.4 \mathrm{yr}$; range, $18-65 \mathrm{yr}$; duration of the disease, 3-48 months) were studied. The diagnosis of GO was based on the presence of the typical clinical features and the finding of enlarged extraocular eye muscles on a coronal MRI of the orbits. No patients had received any previous immunosuppressive treatment. All patients were euthyroid during methylprednisolone pulse therapy. Patients 2, 3, 4 and 9 (Table 1) were diagnosed as having hyperthyroid Graves' disease and GO, and started to receive anti-thyroid drug therapy. They were taking antithyroid drug during methlprednisolone pulse therapy. Patients 1 and 6 had also been diagnosed as having hyperthyroid Graves' disease and GO, and received anti-thyroid drug therapy, but they were euthyroid without antithyroid drug therapy when methylprednisolon pulse therapy was begun. Three patients (patients 5, 7 and 8 in Table 1) had euthyroid Graves' disease. Ophthalmological assessment was performed by the same observer throughout. All GO patients were classified according to the Ophthalmopathy Index (OI) score determined with minor modification from the classification of the American Thyroid Association [18]; five categories

Table 1. Clinical and immunological findings in patients with Grave's ophthalmopathy

\begin{tabular}{|c|c|c|c|c|c|c|c|c|c|c|c|}
\hline Patients & age/sex & $\begin{array}{c}\text { TSAb } \\
(\%) \\
\text { before/after }\end{array}$ & $\begin{array}{c}\text { TBII } \\
(\%) \\
\text { before/after }\end{array}$ & $\begin{array}{c}\text { EMAb } \\
\text { before/after }\end{array}$ & $\mathrm{Mc}-\mathrm{AbTg}$ & $-A b$ & $\begin{array}{l}\text { Changes in } \\
\text { muscle } \\
\text { swelling detected } \\
\text { by } \\
\operatorname{MRI}^{*}(\mathrm{~mm} / \mathrm{mm})\end{array}$ & $\begin{array}{c}\text { OI } \\
\text { (points) }\end{array}$ & $\begin{array}{c}\Delta \mathrm{OI} \\
\text { (points) }\end{array}$ & $\begin{array}{l}\text { Disease } \\
\text { duration } \\
\text { (months) }\end{array}$ & $\begin{array}{l}\text { Exophthalmos** } \\
\text { before/after } \\
(\mathrm{mm})\end{array}$ \\
\hline 1 & $18 / F$ & $333 / 133$ & $7.9 / 10.5$ & $1.25 / 0.90$ & $\times 1600$ & $(-)$ & $52 / 59=0.88$ & 8 & 2 & 24 & $25 / 24$ \\
\hline 2 & $40 / \mathrm{F}$ & $2430 / 759$ & $86.8 / 64.6$ & $1.50 / 1.10$ & $(-)$ & $(-)$ & $49 / 57=0.85$ & 6 & 3 & 48 & $27 / 23$ \\
\hline 3 & $18 / \mathrm{M}$ & $134 / 101$ & $28.9 / 11.0$ & $0.73 / 0.70$ & $\times 25600$ & $(-)$ & ND & 3 & 1 & 48 & $21 / 20$ \\
\hline 4 & $63 / F$ & $314 / 195$ & $24.6 / 15.5$ & $1.10 / 0.90$ & $x 400$ & $(-)$ & ND & 2 & 0 & 12 & $16 / 16$ \\
\hline 5 & $39 / F$ & $260 / 129$ & $14.7 / 19.9$ & $0.60 / \mathrm{ND}$ & $(-)$ & $(-)$ & ND & 2 & 0 & 12 & $17 / 17$ \\
\hline 6 & $65 / \mathrm{M}$ & $1758 / 100$ & $55.9 / 18.5$ & $0.60 / \mathrm{ND}$ & $(-)$ & $(-)$ & ND & 5 & 3 & 3 & $26 / 20$ \\
\hline 7 & $59 / \mathrm{M}$ & $116 / 121$ & $8.3 / 15.5$ & $0.55 / \mathrm{ND}$ & $\times 1600$ & $(-)$ & ND & 3 & 0 & 6 & $19 / 14$ \\
\hline 8 & $38 / \mathrm{F}$ & $141 / 106$ & $16.2 / 7.0$ & $0.20 / \mathrm{ND}$ & $(-)$ & $(-)$ & $30 / 32=0.95$ & 8 & 0 & 24 & $22 / 21$ \\
\hline 9 & $24 / F$ & $114 / 111$ & $29.9 / 23.0$ & $0.10 / \mathrm{ND}$ & $(-)$ & $(-)$ & $24 / 23=1.04$ & 1 & 0 & 11 & $20 / 19$ \\
\hline
\end{tabular}

M, male; F, female. ND, not done. OI, opthalmopathy Index; $\Delta \mathrm{OI}$, changes in OI before and after methylprednisolone pulse therapy. Normal range for TSAb, 55-145\%; TBII, <15\%; EMAb, <0.77. *: changes in muscle swelling after/before methylprednisolone pulse therapy detected by MRI. The sum of muscle thickness from four extraocular muscles of bilateral eyes in each patient was expressed as the ratio of that after/before methylprednisolone therapy. ${ }^{* *}$ : Mean value of right and left eyes measured with a Hertel's exophthalmometer. 
Table 2. Ophthalmopathy Index

\begin{tabular}{|c|c|c|}
\hline Class & Grade (points) & Suggestion for grading \\
\hline 0 & & Only physical signs or symptoms \\
\hline \multirow[t]{7}{*}{1} & & Soft-tissue involvement with symptom or signs \\
\hline & & Subjective symptoms (increased lacrimination, eyepain, photophobia, eyelid swelling) \\
\hline & & Objective symptoms (eyelid edema, retraction, lagophthalmos, conjunctival chemosis and injection) \\
\hline & 0 & Absent \\
\hline & 1 & Minimal \\
\hline & 2 & Moderate \\
\hline & 3 & Marked \\
\hline \multirow[t]{5}{*}{2} & & Exophthalmos \\
\hline & 0 & $<17 \mathrm{~mm}$ \\
\hline & 1 & 17 to $20 \mathrm{~mm}$ \\
\hline & 2 & 21 to $23 \mathrm{~mm}$ \\
\hline & 3 & $>23 \mathrm{~mm}$ \\
\hline \multirow[t]{5}{*}{3} & & Extraocular muscle involvement (usually with diplopia, other symptoms and signs) \\
\hline & 0 & Absent \\
\hline & 1 & Limitation of motion at extremes of gaze \\
\hline & 2 & Evident restriction of motion \\
\hline & 3 & Fixation of a globe or globes \\
\hline \multirow[t]{5}{*}{4} & & Corneal involvement (primarily due to lagophthalmos) \\
\hline & 0 & Absent \\
\hline & 1 & Stippling of cornea \\
\hline & 2 & Ulceration \\
\hline & 3 & Clonding, necrosis, perforation \\
\hline \multirow[t]{5}{*}{5} & & Sight loss \\
\hline & 0 & Absent \\
\hline & 1 & $1.0-0.3$ \\
\hline & 2 & $0.3-0.1$ \\
\hline & 3 & Blindness \\
\hline
\end{tabular}

of findings (exophthalmos, extraocular muscle involvement, corneal involvement, sight loss, and soft tissue involvement) were scored from 1 to 3 according to their severity and activity (Table 2). OI was the sum of the points of five categories; for example, patient 1 had moderate soft tissue involvement (2 points), exophthalmos of $25 \mathrm{~mm}$ (3 points), stippling of cornea (1 point), and evident restriction of eyeball motion ( 2 points), OI being 8 points. Exophthalmos was measured with a Hertel's exophthalmometer.

\section{Treatment protocol}

Patients were admitted to hospital for treatment with intravenous methylprednisolone and had a full clinical examination before treatment. Methylprednisolone was given as $1 \mathrm{~g}$ in $250 \mathrm{ml}$ isotonic saline infused over $1 \mathrm{~h} /$ day for 3 days. Patients were carefully observed for 4 days and a further 3 $\mathrm{g}$ was given. After 4 days' observation, oral prednisolone was begun at a dosage of $40 \mathrm{mg}$ daily together with prophylactic famotidine supplement.
Prednisolone was reduced gradually to $10 \mathrm{mg}$ daily by 4 weeks. Further reduction and discontinuation of prednisolone depended on the clinical assessment at follow up visits.

\section{Antigen preparation}

Rat eye muscle antigen and skeletal muscle were prepared as previously described [5], i.e., the tissue obtained at sacrifice was minced with scissors and homogenized with a mechanical homogenizer in phosphate buffered saline (PBS), $\mathrm{pH}$ 7.4. The homogenate was centrifuged at $800 \times \mathrm{g}$ for $10 \mathrm{~min}$ at $4{ }^{\circ} \mathrm{C}$ to separate off debris, and the supernatant was then further centrifuged at $100,000 \times \mathrm{g}$ for another $60 \mathrm{~min}$. Membrane fractions were resuspended in $1 \mathrm{mg} / \mathrm{ml} \mathrm{PBS}, \mathrm{pH} 7.4$ and stored at $-70^{\circ} \mathrm{C}$ until use.

\section{Anti-eye muscle antibody (EMAb) activity}

EMAb activity was determined as described [5]. Briefly, rat eye muscle membrane separated by a 
SDS-polyacrylamide gel electrophoresis was transferred onto nitrocellulose membrane, followed by incubation with serum of 1:200 diluted with PBS, and detection of human IgG bound to eye muscle membrane-proteins by using the enhanced chemiluminescence (ECL) western blotting system (Amersham Japan Co., Ltd, Tokyo, Japan). The band at $64 \mathrm{kDa}$ was regarded as EMAb. EMAb activity was expressed as the ratio of the density of the $64 \mathrm{kDa}$-band detected by chromato-scanning to that of the $92 \mathrm{kDa}$-non specific band which was always stained with sera of normal controls. The normal range, determined by the mean \pm 2 SD of $\mathrm{EMAb}$ from 7 normal sera, was -0.13 to 0.77 . Any level above 0.77 was regarded as EMAb positive.

Anti-microsomal antibody (Mc-Ab), anti-thyroglobulin antibody $(\mathrm{Tg}-\mathrm{Ab})$, and thyrotropin binding inhibitor immunoglobulin (TBII)

$\mathrm{Mc}-\mathrm{Ab}$ and $\mathrm{Tg}-\mathrm{Ab}$ were measured by a passive hemagglutination assay with commercial kits (Serodia ATG and Serogia AMC, Fujirebio, Tokyo, Japan). TBII was measured with a commercial kit (Baxter Co., Tokyo, Japan; normal, <15\%).

\section{Thyroid-stimulating antibody (TSAb) activity}

TSAb was assayed by measuring cAMP production in porcine thyroid cells as described [21, 22]. Briefly, $5 \times 10^{5}$ cells/dish of porcine thyroid cells obtained by digestion with collagenase $(1 \mathrm{mg} / \mathrm{ml})$ were incubated for $16 \mathrm{~h}$. After removing the medium, $0.3 \mathrm{ml}$ modified hypotonic Hank's medium containing the crude IgG fraction prepared in 15\% polyethylene glycol was added, and the thyroid cells were incubated for $2 \mathrm{~h}$. After the incubation, the amount of cAMP released into the medium was measured with a RIA kit (Yamasa Shoyu Co., Chiba, Japan). The normal range, determined from the mean \pm 2 SD of TSAb from normal sera, was $55-145 \%$. Any level above $145 \%$ was regarded as $\mathrm{TSAb}$ positive.

\section{Magnetic resonance imaging (MRI)}

MRI with a 1.5-T superconductive magnetic unit (SMT-150X; Shimazu, Kyoto, Japan) was performed in all patients before pulse therapy and in $4 \mathrm{GO}$ patients (patients 1, 2, 8 and 9), before and after methylprednisolone pulse therapy. The degree of muscle swelling was assessed as described [17]. The sum of muscle thickness from four extraocular muscles (superior rectus, inferior rectus, lateral rectus, and medial rectus muscle) of bilateral eyes, i.e., the sum of 8 muscle thicknesses in each patient was expressed as the ratio of that after/before methylprednisolone therapy.

\section{Statistical analysis}

The results were analyzed with the Stat View software package. The relationship between parameters was assessed from correlation coefficients determined by linear regression analysis by the method of least mean squares. $P$ values of $<0.05$ were considered as the level of significance.

\section{Results}

Table 1 depicts clinical and immunological find-

Table 3. Reduction in each category of ophthalmopathy index after methylprednisolone pulse therapy

\begin{tabular}{cccccccc}
\hline Patients & Age/Sex & $\begin{array}{c}\text { Ophthalmopathy } \\
\text { index } \\
\text { (points) } \\
\text { before/after }\end{array}$ & $\begin{array}{c}\text { Exophthalmos } \\
\text { (points) } \\
\text { before/after }\end{array}$ & $\begin{array}{c}\text { Extraocular muscle } \\
\text { involvement } \\
\text { (points) } \\
\text { before/after }\end{array}$ & $\begin{array}{c}\text { Corneal } \\
\text { involvement } \\
\text { (points) } \\
\text { before/after }\end{array}$ & $\begin{array}{c}\text { Soft tissue } \\
\text { involvement } \\
\text { (points) } \\
\text { before/after }\end{array}$ & $\begin{array}{c}\text { Sight loss } \\
\text { (points) } \\
\text { before/after }\end{array}$ \\
\hline 1 & $18 / \mathrm{F}$ & $8 / 6$ & $3 / 3$ & $2 / 1$ & $1 / 0$ & $2 / 2$ & $0 / 0$ \\
2 & $40 / \mathrm{F}$ & $6 / 3$ & $3 / 2$ & $0 / 0$ & $1 / 0$ & $2 / 1$ & $0 / 0$ \\
3 & $18 / \mathrm{M}$ & $3 / 2$ & $2 / 1$ & $0 / 0$ & $0 / 0$ & $1 / 1$ & $0 / 0$ \\
4 & $63 / \mathrm{F}$ & $2 / 2$ & $0 / 0$ & $2 / 2$ & $0 / 0$ & $0 / 0$ & $0 / 0$ \\
5 & $39 / \mathrm{F}$ & $2 / 2$ & $1 / 1$ & $0 / 0$ & $0 / 0$ & $1 / 1$ & $0 / 0$ \\
6 & $65 / \mathrm{M}$ & $5 / 2$ & $2 / 1$ & $0 / 0$ & $1 / 1$ & $2 / 0$ & $0 / 0$ \\
7 & $59 / \mathrm{M}$ & $3 / 3$ & $1 / 0$ & $2 / 2$ & $0 / 0$ & $0 / 0$ & $0 / 0$ \\
8 & $38 / \mathrm{F}$ & $8 / 8$ & $3 / 3$ & $2 / 2$ & $1 / 1$ & $2 / 2$ & $0 / 0$ \\
9 & 24/F & $1 / 1$ & $1 / 1$ & $0 / 0$ & $0 / 0$ & $0 / 0$ & $0 / 0$ \\
\hline
\end{tabular}


ings in 9 GO patients. All 9 patients had exophthalmos of over $17 \mathrm{~mm}$ when assessed with an exophthalmometer. Five of these $9 \mathrm{GO}$ patients had positive TSAb, 6 had positive TBII, 3 had positive EMAb, 4 had positive Mc-Ab, and no patient had positive $\mathrm{Tg}-\mathrm{Ab}$. Four of these 9 patients had high OI of over 4 points (patients 1, 2, 6 and 8) before pulse therapy. OI in each category before and after the pulse therapy is shown in Table 3. All four patients with high OI of over 4 points (patients 1, 2, 6 and 8), had exophthalmos of 2 to 3 points, 1 point corneal symptom, 2 point soft tissue involvement, and no sight loss. On the other hand, there were two patients with 2 point extraocular muscle involvement (Patients 1 and 8), but the remaining two had no symptoms in that category (patients 2 and 6). Of these 4 patients, 3 had positive TSAb (333\% in patient $1,2430 \%$ in patient 2 and $1758 \%$ in patient 6 ). All of these 3 patients responded well to methylprednisolone pulse therapy when assessed by $\Delta \mathrm{OI}$ ( 2 points in patients 1 , 3 points in patient 2 , and 3 points in patient 6 ).

Patient 1 was diagnosed as having hyperthyroid GD and GO; she began to receive antithyroid drug when she was 16 years old. Two years later she stopped receiving oral medication because of remission, but her eye symptoms persisted. Before pulse therapy, this patient showed severe exophthalmos when examined with an exophthalmometer and MRI. After pulse therapy, her TSAb, $\mathrm{EMAb}$, and muscle swelling changes detected by MRI decreased (333\% to $133 \%, 1.25$ to 0.90 and 59

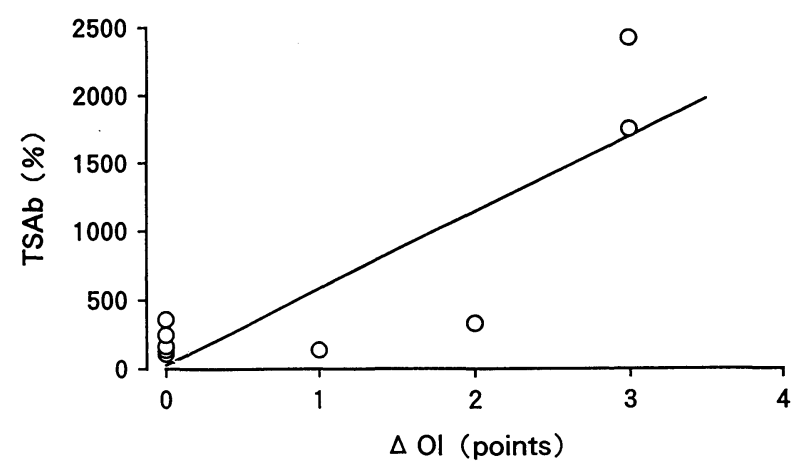

Fig. 1. Relationship between activity of TSAb and reduction in ophthalmopathy index $(\triangle \mathrm{OI})$ in patients with Graves' ophthalmopathy. A statistically significant correlation was observed between them $(r=0.86, P<0.01, n=9)$. $\mathrm{mm}$ to $52 \mathrm{~mm}$, respectively), in accordance with the amelioration of OI (Table 1). Patient 2 was diagnosed as having hyperthyroid GD and GO. She had begun to receive an antithyroid drug when she was 36 years old. She was euthyroid during pulse therapy by oral medication of methimazole, although her TSAb level was extremely high (2430 $\%$ ). After pulse therapy, her TSAb, EMAb and muscle swelling detected by MRI diminished ( $2430 \%$ to $759 \%, 1.50$ to 1.10 and $57 \mathrm{~mm}$ to $49 \mathrm{~mm}$ ). In addition, some of the eye symptoms i.e., increased lacrimination, eye pain and eye lid swelling were remarkably improved in this case. Patient 6 was diagnosed as having hyperthyroid GD and $\mathrm{GO}$; he began to take an antithyroid drug when he was 65 years old. Three months later, he stopped taking oral medication because of remission, but his eye symptoms (increased lacrimination, conjunctival chemosis and injection, and double vision) persisted. After pulse therapy, his TSAb level declined (1758\% to $100 \%)$; this was concomitant with an improvement in the eye symptoms. Patient 8 had 8 point OI severe ophthalmopathy. This patient's eye symptoms did not ameliorate even after methylprednisolone pulse therapy ( 0 point of $\Delta \mathrm{OI})$. Her TSAb and TBII were from negative to weakly positive. The remaining 5 patients (Patients $3,4,5$, 7 and 9) had lower OI of less than 3 points before pulse therapy. These 5 patients poorly responded to the pulse therapy ( 0 to 1 point of $\Delta \mathrm{OI}$ ). Their $\mathrm{TSAb}$ ranged from negative to $314 \%$ at maximum.

The $\Delta \mathrm{OI}$ of $9 \mathrm{GO}$ patients and TSAb before treat-

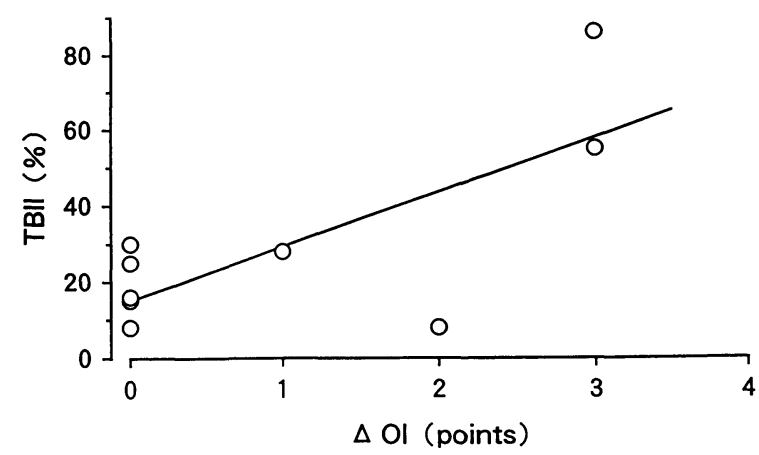

Fig. 2. Relationship between TBII activity and reduction in the ophthalmopathy index $(\Delta \mathrm{OI})$ in patients with Graves' ophthalmopathy. A statistically significant correlation was observed between them $(r=0.75, P<0.01, n=9)$. 
ment correlated significantly $(\mathrm{r}=0.86, P<0.01$, Fig. 1). A statistically significant correlation was observed between the $\Delta \mathrm{OI}$ and TBII levels $(\mathrm{r}=0.75$, $P<0.05$ : Fig. 2), although the relationship between the $\triangle \mathrm{OI}$ and EMAb did not reach significance $(\mathrm{r}=0.58, P=0.10)$. There was no significant correlation between EMAb and TSAb ( $r=0.53, P=0.14)$, or EMAb and TBII $(r=0.42, P=0.26)$.

\section{Discussion}

Although corticosteroids have pronounced efficacy in the treatment of GO, only a few reports of corticosteroids pulse therapy $[9,10]$ have been documented. Thus far there have been no accepted useful markers for the prediction of the efficacy of methylprednisolone pulse therapy. In this series of 9 GO patients treated with intravenous methylprednisolone, 5 did not respond to this medication when assessed by $\Delta$ OI. Among them, patient 8 did not respond to pulse therapy despite severe eye manifestations ( 8 points OI); her TSAb was negative. One patient (patient 3 ) showed only minimal improvement ( 1 point $\Delta \mathrm{OI}$ ). On the other hand, the remaining 3 patients (patients 1,2 and 6) who had strongly positive TSAb levels showed remarkable overall amelioration of ophthalmopathy after pulse therapy. On the other hand, there were no differences among 4 patients with high OI of over 4 points (patients 1, 2, 6 and 8) in titres of Mc$\mathrm{Ab}$ and $\mathrm{Tg}-\mathrm{Ab}$, severity of five categories (see Materials and Methods), and duration of exophthalmos, in the present investigation. These results, and a statistically significant correlation between $\triangle \mathrm{OI}$ and TSAb before treatment suggest that TSAb can be a candidate for the predictive marker of the efficacy of pulse therapy, i.e., we might be able to expect a good response of this therapy in GO patients whose TSAb levels are high. A similar tendency was observed in patients' TBII levels. With one exception (patient 1), TBII levels were almost parallel with TSAb levels, so that TBII levels and $\Delta \mathrm{OI}$ correlated significantly.

The relationship between GO and TSH receptor autoantibody is still controversial. Some investigators have reported that TBII activity was correlated positively with the severity of ophthalmopathy [23]. Others have reported the lack of a significant correlation between TBII and eye disease [24]. However, Kasagi et al. have reported that TSAb were detected in $80 \%$ of euthyroid Graves' patients with ophthalmopathy [25].

In addition, extremely high TSAb activities have been found in patients with severe GO requiring orbital decompression [26]. Tamaki et al. reported two patients with hypothyroid Graves' disease whose eye signs improved in parallel with the decrease in TSAb and TBII noted after the initiation of levothyroxine therapy [27]. These reports suggest the participation of TSAb as a crucial factor in the pathogenesis of GO. A recent study [28] has shown the expression of TSH receptor-specific mRNA and the presence of TSH-binding sites in retro-orbital tissue of $\mathrm{GO}$, suggesting that the orbit of GO can be a putative target for TSAb. Although its precise mechanism(s) has still been uncertain, high TSAb and/or TBII levels might reflect the activity of the immune assault in patients with GO, thus resulting in a good response to corticosteroids pulse therapy.

In patients 1 and 2, muscle swelling evaluated by MRI diminished in accordance with the amelioration of OI. By the same token, presumably, patients 8 and 9, who showed no improvement in OI, had no change in muscle swelling; these results suggest that $\mathrm{OI}$ is able to be used as a reliable and objective index for the evaluation of the severity of GO. It is obvious that the recent advent of MRI has permitted the assessment of fine and subtle changes in ocular muscle swelling in GO patients $[29,30]$. A recent study has shown the usefulness of $T_{2}$ relaxation time measurements with MRI in GO patients for the prediction of systemic corticosteroids and retroorbital radiation therapy [31, 32], suggesting further useful investigation which will be performed in a future study.

The finding of the lack of a correlation between $\mathrm{EMAb}$ and $\triangle \mathrm{OI}$ was unexpected, since EMAb has been reported to reflect the severity of GO [5, 33]. Although the precise reason for this phenomenon has not yet been clarified, it might derive from the selection of subjects and/or differences in the methods employed. It might also be due to the small number of patients studied. Further studies are necessary for a fuller illumination of this area.

\section{Acknowledgments}

The authors thank Dr. T. Shiraishi (Osaka, Japan) for his advice on MRI analysis. 


\section{References}

1. Volpé R (1990) Immunology of human thyroid disease. In: Volpé R (ed) Autoimmune Disease of the Endocrine System. Boca Raton, CRC Press, 73-240.

2. Bahn RS, Heufelder AE (1992) Retroocular fibroblasts: important effector cells in Graves' ophthalmopathy. Thyroid 2: 89-94.

3. Weetman AP (1991) Thyroid associated eye disease: pathophysiology. Lancet 338: 25-28.

4. Utiger R (1992) Pathogeneseis of Graves' ophthalmopathy (editorial). N Engl J Med 326: 17721773.

5. Hiromatsu $Y$, Sato M, Tanaka K, Shoji S, Nonaka K, Chinami M, Fukazawa H (1992) Significance of anti-eye muscle antibody in patients with thyroid associated ophthalmopathy by quantitative western blot. Autoimmunity 14: 9-16.

6. Bahn RS, Gorman CA, Woloschak GE, David CS, Johnson PM, Johnson CM (1987) Human retroocular fibroblasts in vitro. A model for the study of Graves' ophthalmopathy. J Clin Endocrinol Metab 65: 665670.

7. Werner SC (1966) Predonisolone in the emergency treatment of malignant exophthalmos. Lancet 1 : 1004-1007.

8. Marcocci C, Bartalena L, Panicucci M, Marconicini C, Cartei F, Cavallacci G, Laddaga M, Campobasso G, Baschieri L, Pinchera A (1987) Orbital cobalt irradiation combined with retrobulbar or systemic corticosteroids for Graves' ophthalmopathy: a comparative study. Clin Endocrinol (Oxf) 27: 33-42.

9. Nagayama $Y$, Izumi M, Kiriyama T, Yokoyama N, Morita S, Kakezono F, Ohtakara S, Morimoto I, Okamoto S, Nagataki S (1987) Treatment of Graves' ophthalmopathy with high-dose intravenous methylprednisolone pulse therapy. Acta Endocrinol (Copenh) 116: 513-518.

10. Kendall-Taylor P, Crombie AL, Stephenson AM, Hardowick M, Hall K (1988) Intravenous methylprednisolone in the treatment of Graves' ophthalmopathy. Br Med J 297: 1574-1578.

11. Prummel M F, Mourits M P, Berghout A, Krenning E P, Van der Gaag R, Koornineef L, Wiersinga WM (1989) Predonisolone and cyclosporine in the treatment of severe Graves' ophthalmopathy. $N$ Engl J Med 321: 1353-1359.

12. Donaldoson SS, Bagshaw MA, Kriss JP (1973) Supervoltage orbital radiotherapy for Graves' ophthalmopathy. J Clin Endocrinol Metab 37: 276285.

13. Weetman AP, McGregar AM, Ludgate M, Bech L, Lazarus JH, Hall R (1983) Cyclosporin improves Graves' ophthalmopathy. Lancet 2: 486-489.

14. Antonelli A, Saracino A, Alberti B, Canapicchi R,
Cartei F, Lepri A, Laddaga M, Baschieri L (1992) High-dose intravenous immunoglobulin treatment in Graves' ophthalmopathy. Acta Endocrinol (Copenh) 126: 13-23.

15. Kelly W, Longson D, Smithard D, Fawcitt R, Wensley R, Noble J, Keeley J (1983) An evaluation of plasma exchange for Graves' ophthalmopathy. Clin Endocrinol (Oxf) 18: 485-493.

16. Glinoer D, Etienne-Decerf J, Schrooyen M, Sand G, Hoyoux P, Mahieu P, Winand R (1986) Beneficial effects of intensive plasma exchange followed by immunosuppressive therapy in severe Graves' ophthalmopathy. Acta Endocrinol (Copenh) 111: 3038.

17. Nishikawa M, Yoshimura M, Toyoda N, Masaki H, Yonemoto T, Gondou A, Kato T, Kurokawa H, Furumura T, Inada M (1993) Correlation of orbital muscle changes evaluated by magnetic resonance imaging and thyroid-stimulating antibody in patients with Graves' ophthalmopathy. Acta Endocrinol (Copenh) 129: 213-219.

18. Wartofsky L (1992) Classification of eye changes of Graves' disease. Thyroid 2: 235-236

19. Laemmli UK (1970) Cleavage of structural proteins during assembly of the head of bacteriophage T4. Nature 227: 680-684.

20. Towbin H, Staehelin T, Gordon J (1979) Electrophoretic transfer of proteins from polyacrylamide gels to nitrocellulose sheets: procedures and applications. Proc Natl Acad Sci USA 76: 4350-4354.

21. Horimoto $M$, Nishikawa $M$, Uno C, Yoshikawa N, Taniguchi N, Inada M (1988) Relationship among thyrotropin (TSH), thyroid stimulating immunoglobulins, and results of triiodothyrodine (T3) suppression test in patients with Graves' disease. Endocrinol Japon 35: 841-848.

22. Kasagi K, Konishi J, Arai K, Misaki T, Iida Y, Endo K, Torizuka K (1986) A sensitive and practical assay for thyroid-stimulating antibodies using crude immunoglobulin fractions precipitated with polyethylene glycol. J Clin Endocrinol Metab 62: 855-61.

23. Benker G, Kotulla P, Kendall-Taylor P, Emrich D, Reinwein D (1989) TSH binding-inhibiting antibodies in hyperthyroidism: relationship to clinical signs and hormone levels. Clin Endocrinol (Oxf) 30: 1928.

24. Wall JR, Strakoch CR, Fang SL, Ingbar SH, Braverman LE (1979) Thyroid binding antibodies and other immunological abnormalities in patients with Graves' ophthalmopathy: effect of treatment with cyclophosphamide. Clin Endocrinol (Oxf) 10: 79.

25. Kasagi K, Hatabu H, Tokuda Y, Torizuka K (1988) 
Studies on thyrotropin receptor antibodies in patients with euthyroid Graves' disease. Clin Endocrinol (Oxf) 29: 357-366.

26. Morris III JC, Hay ID, Nelson RE, Jiang NS (1988) Clinical utility of thyrotropin-receptor antibody assays: comparison of radioreceptor and bioassay methods. Mayo Clin Proc 63: 707-717.

27. Tamaki H, Amino N, Iwatani Y, Miyai K (1989) Improvement of infiltrative ophthalmopathy in parallel with decrease of thyroid-stimulating antibody (TSAb) activity in two patients with hypothyroid Graves' disease. J Endocrinol Invest 12: 47-53

28. Feliciello A, Porcellini A, Ciullo I, Bonavolonta G, Avvedimento EV, Fenzi G (1993) Expression of thyrotropin-receptor mRNA in healthy and Graves' disease retro-orbital tissue. Lancet 342: 337-338.

29. Just M, Kahaly G, Hinger HP, Roesler HP, Kutzner J, Bayer J, Thelen M (1991) Graves' ophthalmopathy; role of MR imaging in radiation therapy. Radiology 179: 187-190.

30. Hosten N, Sander B, Coordes M, Schubert C,
Sohoerner W, Felix R (1989) Graves' ophthalmopathy, MR imaging of the orbits. Radiology 172: 759-762.

31. Onishi T, Noguchi S, Murakami N, Tajiri J, Harao M, Kawamoto H, Hoshi H, Jinnouchi S, Futami S, Nagamachi S, Watanabe K (1994) Extraocular muscle in Graves' ophthalmopathy: usefulness of $\mathrm{T}_{2}$ relaxation time measurements. Radiology 190: 857-62.

32. Hiromatsu $Y$, Kojima K, Ishisaka N, Tanaka K, Sato M, Nonaka K, Nishimura H, Nishida H (1992) Role of magnetic resonance imaging in thyroid-associated ophthalmopathy: its predictive value for therapeutic outcome of immunosuppressive therapy. Thyroid 2: 299-305.

33. Salvi M, Bernard N, Miller A, Zhang Z, Gardini E, and Wall J R (1991) Prevalence of antibodies reactive with a $64 \mathrm{kDa}$ eye muscle membrane antigen in thyroid-associated ophthalmopathy. Thyroid 1: 207-213. 